Article

\title{
Environment, Identity, and Response to Polluted Landscapes
}

\author{
Susan D. Clayton (1)
}

\author{
Psychology Department, The College of Wooster, Wooster, OH 44691, USA; sclayton@wooster.edu
}

\begin{abstract}
Research indicates that beautiful nature can have positive impacts. Does polluted nature have a corresponding negative impact? This paper presents two experiments investigating the impact of viewing images of natural settings, on a college campus, that do or do not contain litter. The moderating role of environmental identity was also examined. Study 1 showed that landscapes with litter evoked more negative emotions among a sample of 332 U.S. residents on MTurk than did landscapes without litter. Surprisingly, natural landscapes did not have a more positive effect than images of buildings. In Study 2, using an MTurk sample of 310 U.S. residents, results were similar to Study 1 but were qualified by an interaction between condition and EID: those high in EID were more strongly affected by the images. These results suggest that viewing polluted landscapes can have a negative effect on emotions (hedonic wellbeing), and that these effects are stronger among those who have a stronger relationship with nature. There was no evidence for an impact on eudaimonic wellbeing as represented by a sense of meaning, efficacy, or ethicality. Given the continuing degradation of our natural environment, further research on the impacts of polluted landscapes is needed.
\end{abstract}

Keywords: environmental identity; nature; hedonic wellbeing; eudaimonic wellbeing; litter

Citation: Clayton, S.D. Environment, Identity, and Response to Polluted Landscapes. Sustainability 2021, 13, 9422. https://doi.org/10.3390/ su13169422

Academic Editor: Allen R. McConnell

Received: 14 June 2021

Accepted: 19 August 2021

Published: 22 August 2021

Publisher's Note: MDPI stays neutral with regard to jurisdictional claims in published maps and institutional affiliations.

Copyright: (C) 2021 by the author. Licensee MDPI, Basel, Switzerland. This article is an open access article distributed under the terms and conditions of the Creative Commons Attribution (CC BY) license (https:// creativecommons.org/licenses/by/ $4.0 /)$.

\section{Introduction}

A rapidly growing body of literature documents the potential for nature to have a beneficial effect on human health and wellbeing. Both actual [1] and virtual [2] experiences of nature, and even simple exposure to visual images of nature, have been shown to have a variety of positive effects, from improved health [3], to attentional restoration and enhanced cognitive function [4,5], to reduced stress [6]. The well-established impact of nature on positive mood is also indicative of a positive effect on wellbeing [7-9]. Although some of this impact could be due to better air quality, to increased physical activity in green spaces, or to other stress-reducing mechanisms (e.g., calming natural soundscapes [10]), much of it is presumed to be a consequence of the visual information presented by natural environments, because immersion in nature is not required for a positive impact.

Much of the research has contrasted images of attractive nature with images of urban environments. However, this research potentially confounds the attractive vs. unattractive dimension with the natural vs. built dimension. Give the ongoing degradation of natural environments, it is important to understand the potential impact of nature that is not pristine. Some research has examined the impacts of polluted or degraded nature. It seems clear that air pollution has negative impacts on emotions [11], as well as on cognitive performance [12], but this effect could be neurological. Does the visual perception of a polluted environment decrease wellbeing? Pretty et al. [13] found that degraded green environments did not have the restorative impacts that clean alternative scenes provided. Similarly, Wyles et al. [14] found that participants rated beach scenes as less restorative when they were littered. In addition, the participants reported more positive emotions after viewing a photo of a clean natural environment than students who saw the same photo with litter added; see also [15].

Exposure to nature that is not beautiful and is in fact polluted could have negative impacts for a variety of reasons. It could simply fail to provide the pleasure, or the stress 
reduction, associated with beautiful nature-a fairly basic perceptual impact. Perceptual cues could also indicate disorder at a subtle level: research has found that visual disorder, such as crooked lines and asymmetry, increases people's likelihood of cheating on a test, perhaps because it primes mental associations with crooked behavior or requires greater cognitive effort [16]. Visibly polluted nature could also convey a higher-level cognitive message: not only that the landscape is unattractive, but that it is the result of human actions. That is, polluted landscapes could convey a negative message about human nature.

The previously described study of the impact of litter on ratings of beach scenes [14] looked at different types of litter: seaweed, fishing litter, and public litter. The researchers hypothesized that the public litter (e.g., cans, bottles, candy wrappers) would be seen as more intentional and therefore have a more negative effect. Consistent with their hypotheses, public litter was rated more negatively and had a larger detrimental impact on emotion ratings. In qualitative responses, participants described fishing litter as less intentional than public litter, and commented that the public litter was selfish and disrespectful to nature. It seemed that the role of human agency was important in the way participants responded to the litter, and that public litter communicated a negative message about those who did the littering.

Substantial research has shown that litter does convey a message: people's behavior is significantly affected by the presence of litter, although the effect depends on the type of norm that is being considered and communicated [17-19]. The presence of litter may sometimes activate injunctive moral norms as well as descriptive behavioral norms, reminding people that people like them consider littering to be appropriate [17]—or in some cases, inappropriate. In other words, the litter may convey a message that is self-relevant, triggering perceptions about the values or the characteristics of similar others.

In recent years, researchers have emphasized the distinction between hedonic and eudaimonic wellbeing [20]. Hedonic wellbeing is characterized by pleasure and happiness, whereas eudaimonic wellbeing emphasizes a feeling of meaning and purposefulness, a life that fulfills its potential. Exposure to nature appears to have both hedonic and eudaimonic effects: in addition to the effects on positive emotions, researchers have found that exposure to beautiful nature is associated with prosocial tendencies, including empathy, generosity, trust in others, and ethical decision-making [9,21-23]. Experiences of nature may enhance eudaimonic wellbeing by encouraging self-transcendence and a feeling of connection to something larger-that is, by affecting the way in which people think about themselves $[20,21,24]$. Views of natural environments can encourage a sense of humility as well as connection [23]. Might experiences of polluted nature have a parallel negative impact? Might a perception that other people have polluted have a detrimental effect on things like ethical decision-making and on self-perceptions?

A great deal of research and theory has explored the relationships between identity and environment: from place identity, to environmental identity, to the potentially stigmatizing impact of degraded environments [25]. People's experiences in natural environments affect the ways in which they think about themselves. These identities, in turn, affect the ways in which people respond to environments and environmental issues. An environmental identity (EID) $[26,27]$ incorporates an emotional feeling of connection to nature as well as a more cognitive association between oneself and the natural world. There is evidence that early experiences of natural environments are associated with a stronger environmental identity [27]. People with a strong environmental identity should pay more attention to aspects of natural environments as well as showing a stronger emotional reaction.

Research does suggest that feeling connected to nature strengthens the relationship between nature exposure and wellbeing $[28,29]$. The research described above on beach litter [14] examined the impact of connectedness to nature (C2N) on responses to polluted beaches. C2N (which is highly correlated with EID [27]) is considered to reflect an individual's emotional connection to the natural world. In the beach litter study, those who were higher in $\mathrm{C} 2 \mathrm{~N}$ rated the clean and seaweed-covered beach images more positively, and had more positive emotional responses, compared to those low in $\mathrm{C} 2 \mathrm{~N}$; however, $\mathrm{C} 2 \mathrm{~N}$ 
did not make a difference in responses to the littered images. The results suggest that $\mathrm{C} 2 \mathrm{~N}$ heightened the hedonic impact of attractive natural scenery, but the potential impact on eudaimonic wellbeing was not fully explored.

The present studies were designed to investigate whether visibly polluted landscapes have a negative effect on both hedonic and eudaimonic wellbeing, and whether those effects were greater in people who had a personal connection to the environment. Hedonic wellbeing was operationalized as a change in emotional state to reflect an overall more positive tone. Eudaimonic wellbeing was assessed in three ways: ethical decision-making, as in [21]; self-efficacy; and sense of meaning.

It was hypothesized that:

Hypothesis 1 (H1). Images of natural settings with litter would lead to stronger ratings of negative emotions and lower ratings of positive emotions, compared to the same settings without litter. There were no hypotheses regarding specific emotions; however, the possibility of different effects for self-relevant vs. other-relevant emotions was explored.

Hypothesis 2 (H2). Images of natural settings with litter would lead to a decreased sense of meaning, self-efficacy, and ethical decision-making, compared to the same settings without litter.

Hypothesis 3 (H3). These effects would be stronger in those who had a high level of environmental identity.

Images of buildings were included as a control condition: it was expected that responses to natural settings would be more positive than the responses to the buildings, but it was unclear how responses to the littered environments would compare.

Study 1 examined evidence for hedonic and eudaimonic impacts of polluted environments. Study 2 looked at a moderating role of a connection to the environment, as indicated by environmental identity.

\section{Study 1}

\subsection{Method}

\subsubsection{Participants and Procedure}

The Mechanical Turk (MTurk) platform was used to recruit 358 U.S. adult participants. Mechanical Turk is an online service used to connect researchers to research participants, who opt in to complete surveys and other tasks online via a web link in return for a small payment. Although respondents are not a representative sample of the population, they tend to be more diverse than a standard university student sample. After eliminating respondents who did not rate the photos, the final sample was 332, of whom 142 identified as female and 190 identified as male. They ranged in age from under 20 to over 55, with the average age range chosen between $35-44$. They completed the experimental task online: a link sent them to a survey on Qualtrics, where they were randomly assigned to one of three experimental conditions: Nature $(\mathrm{N}=104)$, Litter $(\mathrm{N}=118)$, or Buildings $(\mathrm{N}=110)$. Participants were first shown a series of 10 images corresponding to their experimental condition. To encourage attention to the photographs, the participants were asked to rate the attractiveness of each and the extent to which it seemed prototypical of a college campus (both on 1-7 scales). After rating all the images, they completed the remaining measures.

\subsubsection{Stimuli}

Three slideshows were generated, each of which showed 10 photographs for $6 \mathrm{~s}$ each. Set A (Nature) included attractive photos of a college campus that emphasize the natural setting. Set B (Litter) comprised photos of the same locations that included litter. Set $\mathrm{C}$ (Buildings) presented photographs of buildings around the campus. See Figure 1 for examples. 


\subsubsection{Measures}

Participants rated their current emotional state (the prompt was "Please rate your current mood" on a 1-7 scale) on six items: happy, sad, proud, guilty, angry, grateful. These emotions were selected to balance positive and negative terms and to reflect general mood (happy or sad), self-relevant emotions (proud or guilty), and other-directed emotions (angry or grateful). Participants assessed their sense of meaning, on a 1-5 scale, on three items (taken from [30]; for example, "My life has a clear sense of meaning" Cronbach's alpha $=0.93$ ) and their self-efficacy, on a 0-100 scale, on three items (taken from [31]; for example, "Please rate how certain you are that you can meet your goals in life" Cronbach's alpha $=0.91$ ). All participants were then asked to complete a four-item measure of ethical decision making, adapted from [32], utilizing a 1-7 scale. (Sample item: "Please rate how likely you would be to engage in this behavior: You've waited in line for $10 \mathrm{~min}$ to buy coffee and a muffin at Starbucks. When you're a couple of blocks away, you realize that the clerk gave you change for $\$ 20$ rather than for the $\$ 10$ you gave him. You savor your coffee, muffin and free $\$ 10 . "$ Cronbach's alpha $=0.79$ ).
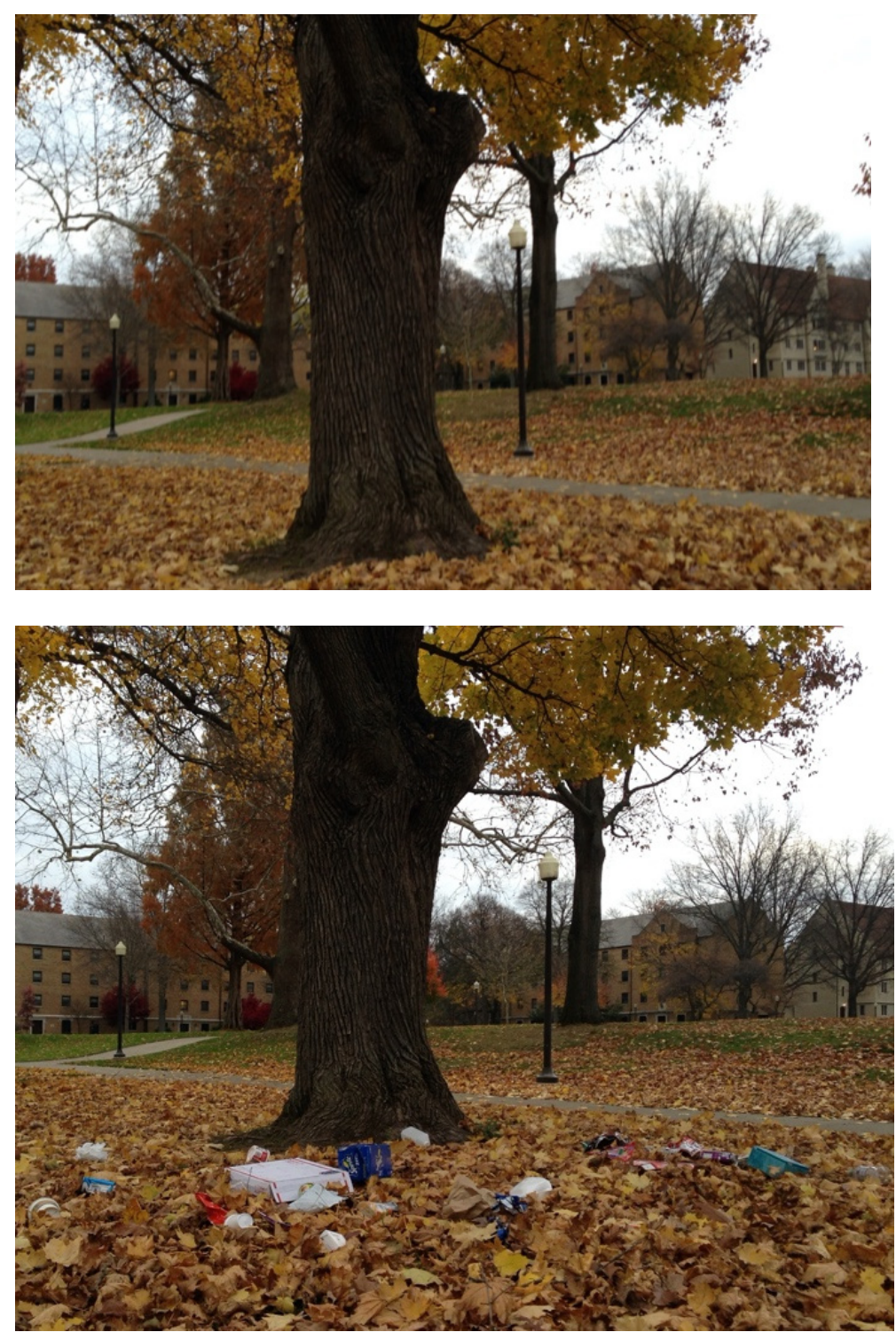

Figure 1. Cont. 




Figure 1. Sample photos.

\subsection{Results}

A factor analysis, followed by varimax rotation, was run on the emotion ratings. Both a scree test and eigenvalues over 1.0 indicated a two-factor solution, with emotions clearly loading on either a positive or a negative factor. See Table 1. Factor scores were retained and used in subsequent analyses.

Table 1. Factor loadings for emotion variables, Study 1.

\begin{tabular}{ccc}
\hline Emotion & Factor 1 (Positive) & Factor 2 (Negative) \\
\hline Happy & 0.84 & -0.30 \\
Proud & 0.88 & 0.03 \\
Grateful & 0.87 & -0.12 \\
Sad & -0.29 & 0.74 \\
Guilty & 0.04 & 0.84 \\
Angry & -0.13 & 0.87 \\
\hline
\end{tabular}

A one-way ANOVA looked for the effect of condition on all variables. As hypothesized, condition had a significant effect on the emotion ratings: for the positive emotion factor, $\mathrm{F}(2,292)=6.26, p=0.002, \eta^{2}=0.041$; for the negative emotion factor, $\mathrm{F}(2,292)=4.32$, $p=0.014, \eta^{2}=0.029$. To explore this effect further, individual emotions were also examined separately. Condition had an effect on all emotions, with the exception of guilt. Although the nature condition tended to get higher ratings for positive emotions and lower ratings for negative emotions, compared with the litter condition, the most positive scores were 
found in the building condition. See Table 2. There were no effects of condition on ethical decision-making, sense of meaning, or general self-efficacy (all F's $<1.0$ ).

Table 2. Effects of experimental condition on individual emotions, Study 1.

\begin{tabular}{cccccccc}
\hline Variable & Build & Nat & Lit & F & df & $p$ & $\eta^{2}$ \\
\hline Happy & $4.98_{\mathrm{a}}$ & $4.73_{\mathrm{a}}$ & $3.98_{\mathrm{b}}$ & 9.67 & 2,320 & $<0.001$ & 057 \\
\hline Proud & $3.79_{\mathrm{a}}$ & $3.06_{\mathrm{b}}$ & $2.95_{\mathrm{b}}$ & 6.04 & 2,317 & 0.003 & 0.037 \\
\hline Grateful & $4.30_{\mathrm{a}}$ & $3.80_{\mathrm{ab}}$ & $3.64_{\mathrm{b}}$ & 3.35 & 2,319 & 0.036 & 0.021 \\
\hline Sad & $1.74_{\mathrm{a}}$ & $1.67_{\mathrm{a}}$ & $2.15_{\mathrm{b}}$ & 3.69 & 2,302 & 0.026 & 0.024 \\
\hline Angry & $1.45_{\mathrm{a}}$ & $0.45_{\mathrm{a}}$ & $2.03_{\mathrm{b}}$ & 7.07 & 2,298 & 0.001 & 0.045 \\
\hline Guilty & $1.57_{\mathrm{a}}$ & $1.39_{\mathrm{a}}$ & $1.53_{\mathrm{a}}$ & 0.73 & 2,301 & 0.484 & 0.005 \\
\hline Note: Means sharing a subscript are not significantly different.
\end{tabular}

Note: Means sharing a subscript are not significantly different.

Pearson's correlations showed that the positive emotions were associated with higher efficacy and meaning. Negative emotions were associated with lower efficacy and meaning, and less ethical decision-making. See Table 3.

Table 3. Correlations among variables, Study 1.

\begin{tabular}{lcccc}
\hline & Negative Emotions & Efficacy & Meaning & Ethics \\
\hline Positive emotions & 0.00 & $0.56^{* * *}$ & $0.24^{* * *}$ & 0.06 \\
Negative emotions & & $-0.20^{* * *}$ & $-0.12^{*}$ & $-0.15^{* *}$ \\
Efficacy & & & $0.46^{* * *}$ & $0.28^{* * *}$ \\
Meaning & & & & $0.27^{* * *}$ \\
\hline
\end{tabular}

${ }^{*} p<0.05,{ }^{* *} p<0.01,{ }^{* * *} p<0.001$.

\subsection{Discussion}

These results suggest a positive hedonic effect from attractive images, with a slight (mostly non-significant) preference for built over natural settings, but a clear negative emotional response to the litter. It may be that the positive response to buildings was due to a perception that they reflect human accomplishment. This explanation is supported by the fact that pride was significantly higher in the building condition than in the other two conditions, whereas other emotions tended to differentiate between buildings and nature, on the one hand, and litter, on the other.

There was no evidence for a eudaemonic effect, that is, an increase in meaning, efficacy, or ethical decision-making. It is worth noting, however, that the emotional response to the images was, in turn, associated with meaning, efficacy, and ethical decision-making. A causal direction for this relationship cannot be concluded from the present studies. However, it is possible that if a more immersive, or longer term, exposure to litter increases anger and decreases happiness, this emotional response could over time lead to a reduced feeling of personal efficacy and meaning and perhaps less ethical behavior.

Given the potential importance of the messages the images convey about human behavior, values, and abilities, it could be that a eudaimonic effect would be limited to those who perceived the images as personally relevant. People with an environmental identity feel connected to the natural environment, pay more attention to it, and are likely to see impacts to the environment as more self-relevant. Study 2 examined whether environmental identity moderated the impact of the environmental images. In order to look at possible practical implications of exposure to litter, it also included a measure of support for environmental policies. 


\section{Study 2}

\subsection{Method}

Again, MTurk was used as a platform to recruit 328 U.S. participants. After removing those who failed to rate the photographs, the sample was 310, including 182 men, 126 women, and 2 who preferred not to choose a category. They ranged in age from under 20 to over 55, with the average age range chosen between 28-34. They completed almost the same procedure as used for Study 1 (Cronbach's alpha for meaning $=0.95$; for efficacy $=0.92$; the ethical decision-making scale was dropped), but filled out two additional measures. First, they completed the short form of the Environmental Identity Scale (Sample item: "I think of myself as part of nature, not separate from it." Cronbach's alpha $=0.90$ ). Second, they rated their support for conservation policies on four items (alpha $=0.92)$ : "We need laws that protect ecosystems;" "We need laws to protect endangered species;" "We need laws to prevent people from polluting the environment;" and "Some parts of the country should be set aside as wilderness areas." The additional measures were rated on a 1-5 scale. The Nature condition had 99 participants; the Litter condition had 111; and the Buildings condition had 100.

\subsection{Results}

As above, emotions were subjected to a factor analysis followed by varimax rotation and they grouped into a positive and a negative factor. See Table 4.

Table 4. Factor loadings for emotion variables, Study 2.

\begin{tabular}{ccc}
\hline Emotion & Factor 1 (Positive) & Factor 2 (Negative) \\
\hline Happy & 0.83 & -0.36 \\
\hline Proud & 0.90 & 0.05 \\
\hline Grateful & 0.89 & -0.06 \\
\hline Sad & -0.27 & 0.85 \\
\hline Guilty & 0.09 & 0.82 \\
\hline Angry & -0.13 & 0.90
\end{tabular}

A one-way ANOVA looked for the effect of condition on all variables. The effect of condition was similar to the findings from Study 1, but the effect on the positive emotion factor was not significant: for the positive emotion factor, F $(2,297)=1.61, p=0.20$, $\eta^{2}=0.011$; for the negative emotion factor, $\mathrm{F}(2,297)=9.70, p<0.001, \eta^{2}=0.061$. Analyses of the individual emotions showed that there were significant effects of condition on the affect variables happy, angry, and sad. Nature received the highest score on happy and the lowest on angry and sad, with the reverse true for the litter condition. See Table 5.

Table 5. Effects of experimental condition on individual emotions, Study 2.

\begin{tabular}{cccccccc}
\hline Variable & Build & Nat & Lit & F & df & $p$ & $\eta^{2}$ \\
\hline Happy & $4.27_{\mathrm{ab}}$ & $4.55_{\mathrm{a}}$ & $3.84_{\mathrm{b}}$ & 3.74 & 2,303 & 0.02 & 0.024 \\
\hline Sad & $1.68_{\mathrm{a}}$ & $1.60_{\mathrm{a}}$ & $2.52_{\mathrm{b}}$ & 13.03 & 2,301 & $<0.001$ & 0.08 \\
\hline Angry & $1.44_{\mathrm{a}}$ & $1.35_{\mathrm{a}}$ & $2.28_{\mathrm{b}}$ & 16.68 & 2,298 & $<0.001$ & 0.10 \\
\hline
\end{tabular}

Note: means sharing a subscript are not significantly different.

To look for a possible interaction between condition and EID, EID scores were dichotomized based on a median split. Two-way analyses of variance showed a nearsignificant interaction effect for both the positive emotion factor $(\mathrm{F}(2,292)=2.90, p=0.056$, $\left.\eta^{2}=0.019\right)$, and the negative emotion factor $\left(\mathrm{F}(2,292)=2.30, p=0.10, \eta^{2}=0.016\right.$. However, when looking only at the emotions for which there was a significant condition effect 
(happy, sad, and angry), there was a significant interaction with EID in all cases: for happy $\left(\mathrm{F}(2,298)=4.48, p=0.01, \eta^{2}=0.029\right)$, angry $\left(\mathrm{F}(2,293)=3.90, p=0.02, \eta^{2}=0.026\right)$, and sad $\left(\mathrm{F}(2,296)=3.07, p=0.05, \eta^{2}=0.02\right)$, such that the impact of condition was stronger for those high in EID. See Figure 2.

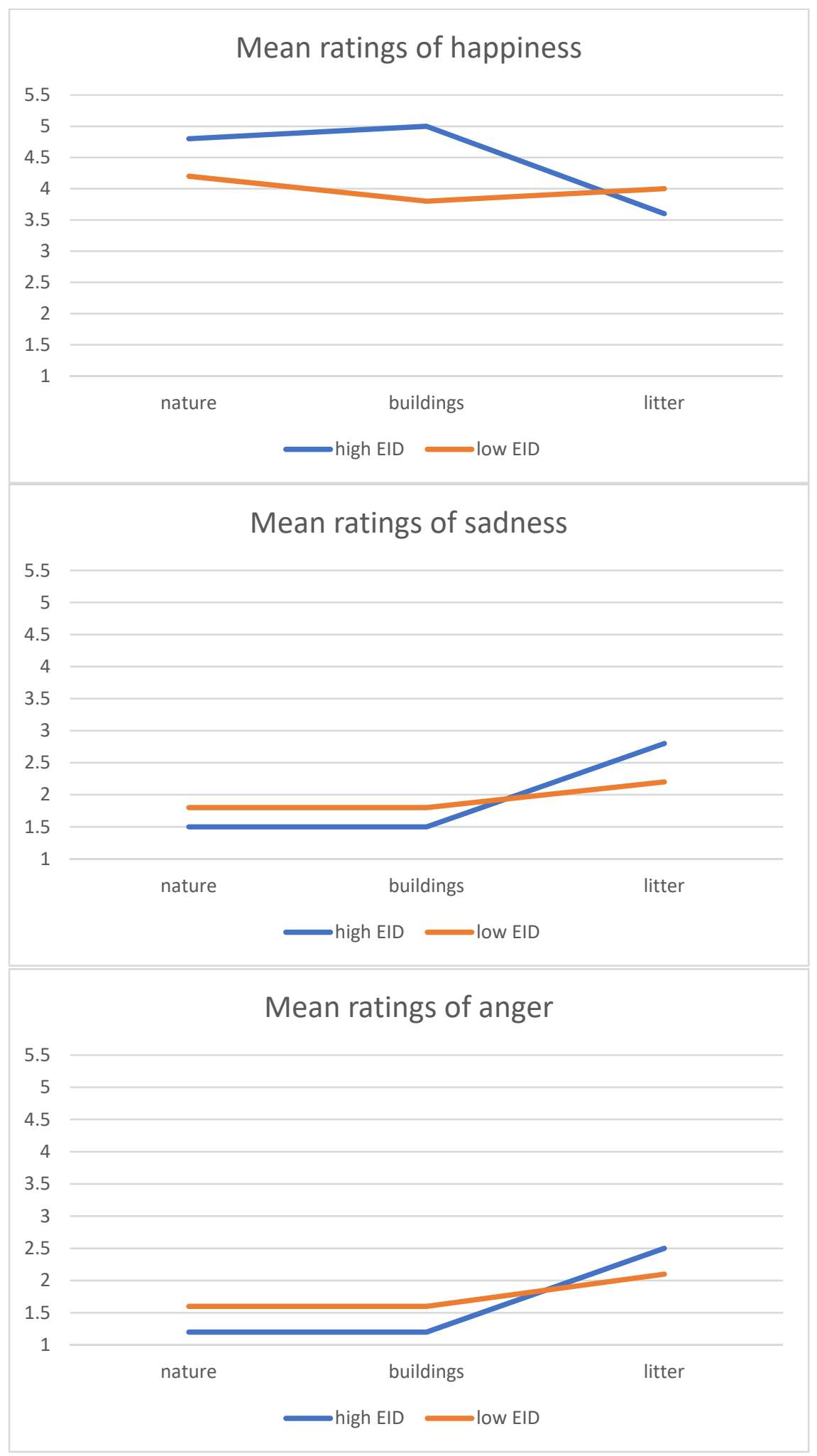

Figure 2. Interaction between condition and EID on happiness, sadness, and anger in Study 2. 
Once again, there were no effects of condition on meaning or efficacy. There were also no effects on support for conservation policies-although the mean rating of support was 4.31 out of 5 , so there may have been a ceiling effect. Correlations, seen in Table 6 , were similar to those in Study 1; in addition, they showed that EID score was positively correlated with overall positive emotions, efficacy, meaning, and support for conservation policies.

Table 6. Correlations among variables, Study 2.

\begin{tabular}{lccccc}
\hline & $\begin{array}{c}\text { Negative } \\
\text { Emotions }\end{array}$ & Efficacy & Meaning & Policy Support & EID \\
\hline Positive emotions & 0.00 & $0.50^{* * *}$ & $0.38^{* * *}$ & -0.03 & $0.18^{* *}$ \\
\hline Negative emotions & & $-0.13^{*}$ & -0.05 & $-0.19^{* *}$ & -0.02 \\
\hline Efficacy & & $0.62^{* * *}$ & $0.13^{*}$ & $0.36^{* * *}$ \\
\hline Meaning & & & 0.01 & $0.18^{* *}$ \\
\hline Policy support & & & & $0.57^{* * *}$ \\
${ }^{*} p<0.05,{ }^{* *} p<0.01,{ }^{* * *} p<0.001$. & & & &
\end{tabular}

\subsection{Discussion}

This study affirmed the negative hedonic impact of images of litter that was seen in Study 1 . In addition, it found that the effect of experimental condition was stronger for those who had a strong environmental identity, meaning that the natural environment was more self-relevant to them. This is consistent with previous research showing that impacts of exposure to natural environments are stronger for those who feel connected to nature $[14,28,29]$. As in Study 1, there was no evidence of a eudaimonic effect.

\section{General Discussion}

These studies confirmed that viewing images of polluted landscapes had a detrimental impact on emotional state: there was a tendency for participants to report lower levels of positive emotions, and a higher level of negative emotions, after viewing images with litter. Thus H1 was supported. In general natural scenes showed no advantage over built scenes. Some previous research has suggested that the affective advantage of natural scenes is based on aesthetic preference rather than an inherent advantage of nature [33], which is consistent with the effect of attractive buildings in the current studies. It is important, given our rapidly urbanizing society, to recognize that built environments can be designed to be restorative [34]. Nature vs. built is not the only distinction that affects people's response; attractive vs. unattractive is also important.

Unlike previous research, and in contrast to $\mathrm{H} 2$, the present studies found no evidence for a eudaimonic impact such that sense of meaning, ethicality, or self-efficacy were lower after viewing scenes with litter compared to scenes without litter. Piff et al. [21] found that the positive effects of awe-inspiring nature were fully mediated by an experience of a "small self;" other research [35] found that the effects of mundane nature on mood and behavior were less than those of awe-inspiring nature. The images of nature in the present studies were not awe-inspiring, but were intended to be commonplace (though attractive) natural settings. In addition, the "exposure" to nature was limited to viewing a series of images on a computer screen. In one study [36], the ability of natural environments to create awe was mediated by the extent to which people felt immersed in those environments. It remains possible that more immersive exposure to polluted nature would have a negative eudaimonic effect, and that the difference between polluted and unpolluted images of awe-inspiring nature would emerge more clearly when applied to awe-inspiring nature (trash beneath a stand of redwood trees, for example).

Supporting H3, Study 2 showed that people high in environmental identity were more strongly affected by the images they viewed. This could indicate either greater attention to the images, or greater care and concern. This is an important reminder that even when it 
comes to something that seems like a reasonably straightforward "main effect," such as exposure to nature, there may well be interactions associated with individual attributes. Longstanding identities that guide the interpretation of environments, such as EID, may be particularly important. National or cultural identities, however, may also be important to consider, as they too can guide the ways in which people attribute meaning to natural and other types of environments. An interesting series of studies that take the malleability of identity into account [37] showed that the effects of exposure to nature images depended on whether or not those images were consistent with a currently active (rural or urban) identity.

This research has implications for human wellbeing. As pollution increases in many parts of the world and the environment becomes more degraded, the psychological impact of such environments may contribute to the growing burden on mental health. The present study only measured emotions and not wellbeing more generally, but it seems possible that repeated or continual exposure to litter may serve as a source of stress. It is worth noting that, in addition to predicting overall support for conservation policies, EID was also positively correlated with positive emotions, efficacy, and sense of meaning across experimental conditions. This study reaffirms the connection between a strong EID and psychological wellbeing. EID can help to satisfy the fundamental human need for belongingness, and could be the focus of programs designed to enhance wellbeing, e.g., among new students.

More broadly, it is possible that this information could help in the advancement of sustainability by serving as a reminder that the goal of protecting the natural environment is a selfish one: people cannot remain unaffected when their environment is degraded. Public health policies that take this information into account could make a stronger push for maintaining healthy ecosystems.

\subsection{Limitations}

The MTurk samples were reasonably diverse but not representative. Personal background may affect response to these images in ways that were not measured.

Similarly, the images used were very far from representing all possible natural, polluted, or built environments. Rather than attempting that impossible task, the decision was made to pick a particular setting (a college campus) and include natural, polluted, and built images in that setting. This may have affected the response, and future studies should sample other settings.

The biggest limitation to the study is the use of computer images as a manipulation. It is quite likely that immersion in polluted landscapes would have a stronger effect. Such research is difficult to do while retaining experimental control over confounding variables and avoiding demand characteristics due to participants' guessing the hypotheses. The emerging use of virtual reality provides an intriguing alternative that could enhance the immersive quality of artificially constructed environments. Nevertheless, field research is necessary to fully examine the impacts of these environments. Given the large number of people who confront degraded environments frequently, even continuously, this research would provide an important contribution to understanding the potential impacts on mental health.

\subsection{Conclusions}

These studies consistently demonstrate a negative impact on mood from a brief exposure to images of littered landscapes as compared to non-littered landscapes. Buildings that were attractive, however, did not have a negative effect. The impact of viewing the images was moderated by environmental identity. Further research could examine whether this is because EID enhances attention to environments, the value for those environments, or both. 
Funding: This research received no external funding.

Institutional Review Board Statement: This research was approved by the College of Wooster Institutional Review Board, Protocol \# 2015/01/8.

Informed Consent Statement: Informed consent was obtained from all subjects.

Data Availability Statement: Data can be obtained from the author.

Conflicts of Interest: The author declares no conflict of interest.

\section{References}

1. Olafsdottir, G.; Cloke, P.; Schulz, A.; Van Dyck, Z.; Eysteinsson, T.; Thorleifsdottir, B.; Vögele, C. Health benefits of walking in nature: A randomized controlled study under conditions of real-life stress. Environ. Behav. 2020, 52, 248-274. [CrossRef]

2. Yu, C.P.; Lee, H.Y.; Lu, W.H.; Huang, Y.C.; Browning, M.H. Restorative effects of virtual natural settings on middle-aged and elderly adults. Urban For. Urban Green. 2020, 56, 126863. [CrossRef]

3. Soga, M.; Evans, M.J.; Tsuchiya, K.; Fukano, Y. A room with a green view: The importance of nearby nature for mental health during the COVID-19 pandemic. Ecol. Appl. 2021, 31, e2248. [CrossRef]

4. Berman, M.G.; Jonides, J.; Kaplan, S. The cognitive benefits of interacting with nature. Psychol. Sci. 2008, 19, 1207-1212. [CrossRef]

5. Bratman, G.N.; Hamilton, J.P.; Daily, G.C. The impacts of nature experience on human cognitive function and mental health. Ann. N. Y. Acad. Sci. 2012, 1249, 118-136. [CrossRef]

6. Hartig, T.; Evans, G.W.; Jamner, L.D.; Davis, D.S.; Gärling, T. Tracking restoration in natural and urban field settings. J. Environ. Psychol. 2003, 23, 109-123. [CrossRef]

7. Carrus, G.; Scopelliti, M.; Lafortezza, R.; Colangelo, G.; Ferrini, F.; Salbitano, F.; Agrimi, M.; Portoghesi, L.; Semenzato, P.; Sanesi, G. Go greener, feel better? The positive effects of biodiversity on the well-being of individuals visiting urban and peri-urban green areas. Landsc. Urban Plan. 2015, 134, 221-228. [CrossRef]

8. Sandifer, P.A.; Sutton-Grier, A.E.; Ward, B.P. Exploring connections among nature, biodiversity, ecosystem services, and human health and well-being: Opportunities to enhance health and biodiversity conservation. Ecosyst. Serv. 2015, 12, 1-15. [CrossRef]

9. White, M.P.; Pahl, S.; Wheeler, B.W.; Depledge, M.H.; Fleming, L.E. Natural environments and subjective wellbeing: Different types of exposure are associated with different aspects of wellbeing. Health Place 2017, 45, 77-84. [CrossRef] [PubMed]

10. Uebel, K.; Marselle, M.; Dean, A.J.; Rhodes, J.R.; Bonn, A. Urban green space soundscapes and their perceived restorativeness. People Nat. 2021, 3, 756-769. [CrossRef]

11. Zheng, S.; Wang, J.; Sun, C.; Zhang, X.; Kahn, M.E. Air pollution lowers Chinese urbanites' expressed happiness on social media. Nat. Hum. Behav. 2019, 3, 237-243. [CrossRef]

12. Zhang, X.; Chen, X.; Zhang, X. The impact of exposure to air pollution on cognitive performance. Proc. Natl. Acad. Sci. USA 2018, 115, 9193-9197. [CrossRef]

13. Pretty, J.; Peacock, J.; Sellens, M.; Griffin, M. The mental and physical health outcomes of green exercise. Int. J. Environ. Health Res. 2005, 15, 319-337. [CrossRef]

14. Wyles, K.J.; Pahl, S.; Thomas, K.; Thompson, R.C. Factors that can undermine the psychological benefits of coastal environments: Exploring the effect of tidal state, presence, and type of litter. Environ. Behav. 2016, 48, 1095-1126. [CrossRef]

15. Poškus, M.S.; Valickienė, R.P.; Kuzinas, A. The effects of descriptive imagery and appeals on emotions and intentions related to pro-environmental behavior. Sustainability 2019, 11, 5257. [CrossRef]

16. Kotabe, H.P.; Kardan, O.; Berman, M.G. The order of disorder: Deconstructing visual disorder and its effect on rule-breaking. J. Exp. Psychol. Gen. 2016, 145, 1713. [CrossRef] [PubMed]

17. Cialdini, R.B.; Reno, R.R.; Kallgren, C.A. A focus theory of normative conduct: Recycling the concept of norms to reduce littering in public places. J. Personal. Soc. Psychol. 1990, 58, 1015. [CrossRef]

18. Keizer, K.; Lindenberg, S.; Steg, L. The spreading of disorder. Science 2008, 322, 1681-1685. [CrossRef]

19. Schultz, P.W.; Bator, R.J.; Large, L.B.; Bruni, C.M.; Tabanico, J.J. Littering in context: Personal and environmental predictors of littering behavior. Environ. Behav. 2013, 45, 35-59. [CrossRef]

20. Olivos, P.; Clayton, S. Self, nature and wellbeing: Sense of connectedness and environmental identity for quality of life. In Handbook of Environmental Psychology and Quality of Life Research; Fleury-Bahi, G., Pol, E., Navarro, O., Eds.; Springer: New York, NY, USA, 2016; pp. 107-126.

21. Piff, P.K.; Dietze, P.; Feinberg, M.; Stancato, D.M.; Keltner, D. Awe, the small self, and prosocial behavior. J. Personal. Soc. Psychol. 2015, 108, 883. [CrossRef] [PubMed]

22. Zelenski, J.M.; Dopko, R.L.; Capaldi, C.A. Cooperation is in our nature: Nature exposure may promote cooperative and environmentally sustainable behavior. J. Environ. Psychol. 2015, 42, 24-31. [CrossRef]

23. Zhang, J.W.; Piff, P.K.; Iyer, R.; Koleva, S.; Keltner, D. An occasion for unselfing: Beautiful nature leads to prosociality. J. Environ. Psychol. 2014, 37, 61-72. [CrossRef]

24. Pritchard, A.; Richardson, M.; Sheffield, D.; McEwan, K. The relationship between nature connectedness and eudaimonic well-being: A meta-analysis. J. Happiness Stud. 2020, 21, 1145-1167. [CrossRef]

25. Clayton, S.; Opotow, S. (Eds.) Identity and the Natural Environment; MIT Press: Cambridge, MA, USA, 2003. 
26. Clayton, S. Environmental identity: A conceptual and an operational definition. In Identity and the Natural Environment; Clayton, S., Opotow, S., Eds.; MIT Press: Cambridge, MA, USA, 2003; pp. 45-65.

27. Clayton, S. (Ed.) Environment and identity. In Oxford Handbook of Environmental and Conservation Psychology; Oxford University Press: New York, NY, USA, 2012; pp. 164-180.

28. Capaldi, C.A.; Passmore, H.A.; Ishii, R.; Chistopolskaya, K.A.; Vowinckel, J.; Nikolaev, E.L.; Semikin, G.I. Engaging with natural beauty may be related to well-being because it connects people to nature: Evidence from three cultures. Ecopsychology 2017, 9, 199-211. [CrossRef]

29. Martin, L.; White, M.P.; Hunt, A.; Richardson, M.; Pahl, S.; Burt, J. Nature contact, nature connectedness and associations with health, wellbeing and pro-environmental behaviours. J. Environ. Psychol. 2020, 68, 101389. [CrossRef]

30. Steger, M.F.; Frazier, P.; Oishi, S.; Kaler, M. The meaning in life questionnaire: Assessing the presence of and search for meaning in life. J. Couns. Psychol. 2006, 53, 80-93. [CrossRef]

31. Bandura, A. Guide for constructing self-efficacy scales. In Self-Efficacy Beliefs of Adolescents; Pajares, F., Urban, T., Eds.; Information Age Publishing: Charlotte, NC, USA, 2006; pp. 307-337.

32. Detert, J.R.; Treviño, L.K.; Sweitzer, V.L. Moral disengagement in ethical decision making: A study of antecedents and outcomes. J. Appl. Psychol. 2008, 93, 374. [CrossRef]

33. Meidenbauer, K.L.; Stenfors, C.U.; Bratman, G.N.; Gross, J.J.; Schertz, K.E.; Choe, K.W.; Berman, M.G. The affective benefits of nature exposure: What's nature got to do with it? J. Environ. Psychol. 2020, 72, 101498. [CrossRef]

34. Lindal, P.J.; Hartig, T. Architectural variation, building height, and the restorative quality of urban residential streetscapes. J. Environ. Psychol. 2013, 33, 26-36. [CrossRef]

35. Joye, Y.; Bolderdijk, J.W. An exploratory study into the effects of extraordinary nature on emotions, mood, and prosociality. Front. Psychol. 2015, 5, 1577. [CrossRef] [PubMed]

36. Ballew, M.T.; Omoto, A.M. Absorption: How nature experiences promote awe and other positive emotions. Ecopsychology 2018, 10, 26-35. [CrossRef]

37. Morton, T.A.; van der Bles, A.M.; Haslam, S.A. Seeing our self reflected in the world around us: The role of identity in making (natural) environments restorative. J. Environ. Psychol. 2017, 49, 65-77. [CrossRef] 